\title{
Mate Guarding in a Caribbean Village
}

\author{
Mark V. Flinn \\ Department of Anthropology, University of Michigan
}

\begin{abstract}
Behavioral observation, economic, and genealogical data collected in a rural Trinidadian village indicate: (1) males courting the same females have higher rates of agonistic interactions (e.g., arguing, fighting) with each other than they do with other males; (2) females courting the same males do not have higher rates of agonistic interactions with each other than they do with other females; (3) exclusive (monogamous) mating relationships have lower rates of agonistic interactions than nonexclusive (polygamous) mating relationships; (4) coresident mates interact more frequently when the female is fecund; (5) coresident mates have higher rates of agonistic interactions when the female is fecund; (6) males with fecund mates have higher rates of agonistic interactions with other unrelated males than do males with infecund mates; (7) fecund females do not have higher rates of agonistic interactions with other females than do infecund females; and (8) females do not guard prosperous males (those from households with 6 or more acres of land) more intensely than poorer males. These results suggest that mate guarding is an important aspect of reproductive competition, and that there are significant male/female differences in mate guarding strategies in this human population.
\end{abstract}

KEY WORbS: Mate guarding; Behavioral scan; Caribbean village.

Jealously normally runs so high in Dobu that a man watches his wife closely, carefully timing her absences when she goes to the bush for natural functions. And when it is time for women's work in the gardens here and there one sees a man with nothing to do but stand sentinel all day ... (Reo Fortune 1963:7)

This stress upon the biological tie of parenthood can thus be seen to relate to a variety of phenomena . . . the father's doubts about whether a child is his, and his watchfulness and wariness... (Hyman Rodman 1971:138)

In fact, constraint of female sexuality by the threat of male violence appears to be cross-culturally universal. (Martin Daly and Margo Wilson 1983:295)

Received December 3, 1985; revised September 10, 1986. Address reprints requests to: Mark V. Flinn, Department of Anthropology, University of Michigan, Ann Arbor, MI 48109.

Paper delivered at the American Anthropological Association meetings, Dec. 4, 1984.

Ethology and Sociobiology $9: 1-28$ (1988)

(C) Elsevier Science Publishing Co., Inc., 1988

$0162-3905 / 88 / \$ 03.50$

52 Vanderbilt Ave., New York, New York 10017 


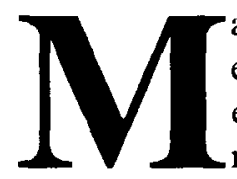
ales in a wide range of species spend considerable time and energy trying to control the mating activities of females. For example, among phasmids (Orthopterous insects), "the male may act as a living chastity belt for the female" (Thornhill and Alcock 1983:346) by remaining attached to her in the copulatory position for as long as 72 days (Sivinski 1978)! Such behavior is commonly referred to by biologists as "mate guarding." Although it is less common, females in some species also guard their mates, evidently to prevent the loss of resources or parental care provided by males (e.g., Jenni 1974; Tenaza 1975).

Humans have developed an elaborate arsenal of devices for the apparent purpose of mate guarding (Dickemann 1981), including chastity belts, eunuch harem guards, and genital mutilations such as clitoridectomy and infibulation (e.g., Hosken 1982; Kouba and Muasher 1985). Other more simple day-today behaviors may have a similar function.

During 1978 and 1979-1980 I spent nine months conducting ethnographic field research in rural Trinidad, mostly in the village of "Grande Anse." In Grande Anse I frequently observed behaviors that had the apparent purpose of controlling (with or without conscious intent) the sexual activities of mates. The means by which villagers attempted to guard mates included physical violence directed toward a mate or a mate's potential suitor(s), maintaining close proximity to a mate, economic sanctions, and verbal threats of the above behaviors.

The objective of this paper is to examine if the efforts to control mating activities in Grande Anse are consistent with predictions from evolutionary models of mate guarding, and if not, what modifications to the models are necessary.

\section{MATE GUARDING THEORY}

Mate guarding theory is based on the proposition that the risks, time, and energetic costs of mate guarding behavior can obtain compensating benefits from an increased probability of reproduction. Mates may be guarded either by restricting the mate, or by restricting other individuals attempting to gain access to the mate. Male and female mate guarding strategies differ in that the advantages for males of guarding a mate(s) include increased mating success and increased confidence of paternity (if paternal investment is made), whereas for females the primary benefit is increased parental investment from the guarded male(s).

The differences in male and female mate guarding strategies may be viewed as an outcome of two fundamental differences in male and female reproductive strategies. First, males usually increase fitness by multiple matings, whereas females usually increase fitness by obtaining additional resources (Darwin 1871; Bateman 1948; Trivers 1972). Hence males are expected to guard mates when it increases their mating success, whereas 
females are expected to guard mates when it increases the quantity or quality of resources that they receive from a male (e.g., maintenance of a monopoly on a male's parental investment). Second, internal fertilization rcsults in a significant difference between males and females in their ability to identify genetic offspring (Alexander 1974; Alexander and Borgia 1979). Among humans, maternity is never in doubt, whereas paternity may be less certain. If males provide parental investment (as is common in most human societies), then we expect males to guard more ardently. Females, in contrast, stand to gain no additional confidence of maternity from guarding a mate.

The advantages and disadvantages of being guarded also differ for males and females. For females, the costs of being guarded by males include restriction of mate choice and loss of resources obtainable from additional mates. The benefits may include protection from sexual harassment, and prevention of infanticide (e.g., Hrdy 1979; Daly and Wilson 1981; Smuts 1985). For males. polygynous mating opportunities may be lost as a result of aggressive guarding by a female discouraging other females from mating with her guarded mate. ${ }^{1}$ There are no obvious benefits to males from being guarded.

The costs of restricting the activities of a mate may differ for males and females because of sexual dimorphisms in size, strength, weapon use, or kin residence patterns. Attempts to discourage rivals may also differ in costs for males and females. For males, intrasexual competition for mates may be quite risky and entail high rates of mortality (e.g., Chagnon 1983; Daly and Wilson 1982, 1983; Thornhill and Thornhill 1983). Female competition for mates usually is more subtle among humans, only rarely involving physical combat (Irons 1983).

Studies of nonhuman species suggest that mate guarding behaviors are most likely to occur when the probability of reproduction with the "guarded" mate is high, i.e., the guarded mate is fecund, or soon will be (see Trivers 1972; Parker 1974; Wilson 1975; Borgia 1979; Manning 1980; Thornhill and Alcock 1983; Emlen and Oring 1977; Vehrencamp and Bradbury 1984; Trivers 1985; Birkhead et al. 1985). In a study of bank swallows (Riparia riparia), Beecher and Beecher (1979) found that males follow their

\footnotetext{
${ }^{1}$ We may expect this conflict of interest between the sexes resulting from guarding by females to be greatest when there is high variance among males in the control of important heritable resources. Hede males with large amounts of resources may be attractive to a large number of females (Orians 1969; Verner and Willson 1966), but the current mate(s) of such a male will want to restrict his mating success so that more of the male's resources are invested in their offspring. Hence we might expect male/female dominance behavior to be most intense where there is polygyny by high-status or wealthy males (e.g., high-status groups in Indian and Arabic societies; cf. Dickemann 1981; Flinn 1981; Flinn and Low 1986; Hartung 1982; Sanday 1981; Schlegel 1972; Whyte 1978; Paige and Paige 1981), because such males will benefit from dominance by reducing female interference (guarding) as well as raising confidence of paternity Genital mutilations may remove an important source of female power in the marital relationship, the threat of cuckoldry. "Circumcised" females may be especially desirable wives for highstatus males in polygynous societies because such females may be less capable of interfering with their husband's sexual activities, as well as being less likely to cuckold him. Menstrual seclusion may serve a similar function (Asherian, et al., 1986).
} 
mates much more closely during the 4 or 5 days in which the females are fertile, attempting to repel other suitors or rapists. Birkhead (1982) obtained similar results in a study of magpies Pica pica. Among Ring doves (Streptopelia risoria), males maintain close proximity to their mates in order to prevent cuckoldry (Lumpkin 1981; Lumpkin et al. 1982; Zenone et al. 1979).

The conditions favoring mate guarding discussed above vary in significant ways among individuals residing in Grande Anse, providing a "natural experiment" to test hypotheses from evolutionary theory. This paper focuses on two basic aspects of mate guarding:

First, as an objective evaluation of "mate competition" in this population, behavioral data concerning intrasexual aggression are examined. The general prediction here is that individuals competing for the same mate behave more agonistically towards one another than towards other individuals (see Methods and Field Techniques for definitions).

Second, behavioral data are analyzed to determine whether intra- and intersexual aggression varies according to the reproductive potential (fecundity) of females. The general prediction here is that females of high reproductive potential are guarded more intensely by their mates than are females of low reproductive potential.

Before presenting the results I will first briefly describe the study site and the methods and field techniques so as to provide a basis for understanding the data base.

\section{THE STUDY SITE}

The village of "Grande Anse" is located on the northern coast of Trinidad. It is isolated from the more heavily populated and economically developed central and western areas of the country by the steep and densely vegetated slopes of the Northern Range, which rise directly from the sea. Most of the 342 inhabitants live in the small pocket of relatively level alluvial deposits from the Grande Anse River. The surrounding hillsides are cultivated with cocoa, coffee, bananas, and citrus as cash crops, and cassava, corn, dasheen, and vine tubers as subsistence items. Further inland the topography is too severe for efficient cultivation. Most of this land is undeveloped government forest reserve.

The village founders arrived about 1860 from Venezuela in small sailing canoes (Harrison 1979). Later, immigrants rowed or sailed from the nearby (40 kilometers) island of Tobago. By 1900 the community was thriving, with most villagers owning or squatting on plots of land, cultivating cocoa and subsistence crops. During the cocoa boom of the early 1900 s outside interests purchased tracts of land and employed village labor. However the cocoa market crashed during the 1920 s and never recovered. Workers were laid off, and the smaller cocoa plots abandoned. Diversification into other crops such as coffee, citrus, and bananas helped to maintain the agricultural base 
of the village, but it never returned to the prosperity of the early cocoa days. Census data indicate that the village population has slowly declined, largely due to emigration to more developed areas (Harrison 1979).

There are a variety of ways to make a living in Grande Anse. Some are more lucrative than others. Most villagers have several part-time occupations, such as cocoa cultivation, fishing, carpentry, road work (government job), and shopkeeping. A majority of adult villagers have rights to cultivated land and spend some effort growing cash crops (eg., cocoa, coffee) and subsistence crops. But the profits are slim and the work is hard so that cultivation is the primary occupation of very few villagers today (about $13 \%$ of adult males, $8 \%$ of adult females).

\section{METHODS AND FIELD TECHNIQUES}

During July and August 1978, and October 1979 through April 1980, I conducted field research in the village of "Grande Anse"' and surrounding areas. Five types of data were gathered that are useful for testing hypotheses from mate guarding theory: (1) behavioral observations, (2) genealogies, (3) mating histories, (4) land ownership, and (5) residence.

\section{Day-to-Day Behavior}

I collected data detailing the day-to-day behavior of the villagers with a "behavioral observation route instantaneous scan sample" procedure (cf. Munroe and Munroe 1971; Monroe et al. 1983; Altmann 1974; Johnson 1975; Denham 1978; Hames 1979; Rogoff 1985; Gross 1984; Betzig and Turke 1986). Scan data are particularly appropriate for the study of mating relationships because they can provide objective measures of behavior that would be difficult or unreliable to obtain by questionnaire techniques (cf. Johnson 1978; Blurton-Jones 1972; Pelto and Pelto 1970, 1975).

The behavior scan procedure was as follows: I traveled a set $4.7-\mathrm{km}$ route through the study site once or twice daily, starting at a randomly determined time and place on the route. The route went through the entire village, passing within 20 meters of each inhabited house and each community structure (e.g. church, cricket field, water outlets). Because village houses are quite open, and because the route passed close by each house, observability was excellent. Each time an individual was observed, I recorded (with a notebook and/or tape recorder) the time, location, individual, and behavior. This information was coded within 48 hours onto computer format sheets. For each "observation," the date, time, one of 1,375 location codes, one of 480 individual identification numbers, and one or more of 475 behavior codes were numerically recorded for computer analysis. For example, on February 16, 1980 at 12:03 PM I observed Kelvin L. and Valerie 
P. (who had been coresiding for 11 months) sorting rice together on the porch of their house. This observation was coded:

\begin{tabular}{ccccc}
\hline Date & Time & Location & Individual & Behavior \\
\hline 160280 & 1203 & 0581 & 0581 & 334 \\
160280 & 1203 & 0581 & 0582 & 334 \\
\hline
\end{tabular}

I recorded about 33,000 observations in the above fashion over a period of 6 months (173 scan routes on 152 days). Of these observations, 24,577 form the data base used in this paper. I have excluded observations recorded during the first 2 weeks of the procedure, observations recorded during scan routes in which less than $50 \%$ of the villagers were observed, observations of visitors to the village, and observations of unidentified individuals.

A substantial number of the observations $(16,541$, or $66 \%$ ) involved interactions between two or more individuals, as in the above example of Kelvin and Valarie sorting rice together. Objectively defining "interaction" was not a simple task. In general, if individuals were (1) communicating to one another, (2) touching or in close proximity (less than 1 meter) to each other, or (3) engaged in tasks that required mutual cooperation (e.g., hauling in a fish net), then I recorded the observation as an interaction. Most interactions involved dyads (two individuals), although some multiple party interactions were recorded (e.g., three men rolling a $\log$ ).

An advantage of behavioral scan data is that they allow a numerical description of the frequencies and types of behavior for specific individuals. For example, these data can be analyzed by computer to provide an objective, quantitative description of the interactions that mating relationships entail.

In this paper three measures of mate guarding are computed from the scan data: (1) intrasexual aggression was determined by computing the frequency of agonistic interactions ${ }^{2}$ between individuals competing for the same mates (see Mating Histories below), (2) the proportion of time that mates spend in proximity to one another was determined by computing the frequency of behavioral interaction between coresident mates, and (3) intersexual aggression between mates was determined by computing the frequency of agonistic interactions between coresident mates. These three measures are used to provide objective measures of the extent to which mates were being guarded. They are similar to the measures used in the nonhuman studies of mate guarding cited earlier (e.g. Beecher and Beecher 1979). In

\footnotetext{
${ }^{2}$ Agonistic interactions are defined as those behaviors that involved physical or verbal combat (e.g., "cussing someone," "fighting with a broken bottle") or expressions of injury inflicted by another individual (e.g., "screaming in pain or anguish," "crying"). Twenty-six of the behavior codes were included in this category (see Appendix). Of the total of 24,577 observations, $1,218(4.8 \%)$ involved agonistic interactions. Most of these were verbal $(92.5 \%)$. As a frame of reference, I subjectively consider the level of agonism in Grande Anse to be about equal to that of an American middle-class neighborhood.
} 
the following section (Results) these measures are used to test hypotheses concerning male/female differences in mate guarding, and variation in the intensity of mate guarding according to the reproductive potential (fecundity) of females.

\section{Genealogical Information}

Genealogies are an important source of information regarding mating relationships. In this paper genealogical information is used to determine several variables relevant to the analysis of mate guarding: (1) the age of individuals, (2) the reproductive potential (fecundity) of females, and (3) the identities of relatives and nonrelatives.

To collect genealogies I interviewed informants from each household, usually adult females, obtaining the names, genealogical relationships, ages, and current residences of all the relatives (blood and affinal) that they could remember (see Chagnon 1974; McGoldrick and Gerson 1985). These interviews were well received, most villagers seeming pleased that someone was interested in their family history (cf. Chagnon 1983). Upon returning from the interview, I assigned unique identification numbers (I.D.) to each individual collected in the genealogies and put all of the above information for each individual on $3^{\prime \prime} \times 5^{\prime \prime}$ index cards. Discrepancies and questionable paternity assignments were checked by additional interviews. The genealogical information was analyzed by computer (after returning to the United States) for cross reference with the behavioral scan data.

Adults are defined as males 20-45 years of age and females 18-40 years of age. These ages were subjectively chosen on the basis of economic independence, residence, and reproductive capability. All individuals considered in this paper were "adults." Changing the definition of adult by 5 years up or down does not substantially change the statistical significance of any of the results presented in this paper.

Fecund and infecund females are defined as follows: All females aged 18-40 were grouped into six categories of reproductive condition: (no. 1) no birth yet, (no. 2) first 5 months of pregnancy, (no. 3) last 4 months of pregnancy, (no. 4) less than 12 months since giving birth, (no. 5) more than 12 months but less than 48 months since giving birth, and (no. 6) more than 48 months since giving birth. Category 2 may be underrepresented because of the difficulties in identifying women in the first stages of pregnancy. Females in reproductive conditions 1 and 5 ("no birth yet" and "more than 12 but less than 48 months since birth") are defined as "fecund." On the other hand, females in conditions $2,3,4$, and 6 ("first half of pregnancy," "last half of pregnancy," "less than 12 months since birth," and "more than 48 months since last birth") are defined as "infecund" (for discussion of reduced fecundity during lactation, i.e., condition 3, see Konner and Worthman 1980; Harrell 1981; Howie et al. 1981).

I also considered using age as a measure of female reproductive potential 
(fecundity). The scan data do indicate that young females are guarded more intensely, but there are so many other plausible explanations for this association (e.g., young age of the males, or that mating relationships with younger women might be less "established") that I did not think it a useful test.

To control for incidental effects of age, the statistical tests presented in this paper are repeated within approximately 8 year age categories (for females: $18-25,26-33,34-40$ years of age; for males: $20-27,28-35,36-45$ years of age) where it is appropriate to do so.

\section{Mating Histories}

Another objective of the fieldwork was to gather accurate mating histories. Collection of mating histories occurred over the entire period of the field study, and overlapped with the collection of accurate genealogies. For both sets of data I found it useful to seek redundant information from several informants, to allow for cross-checking (Chagnon 1974). An additional source of information was the registry of births. This was not very reliable because it sytematically avoided illegitimacy by ascribing paternity to a woman's legal husband. The registry was, however, useful for acquiring birth dates. Information about recent and current mating relationships was much more reliable and complete than that for past relationships, partly because informants' memories were fresher, and partly because they were observable at the time of the study.

The mating/courting relationships analyzed in this paper were widely recognized by the villagers, were readily observable (i.e., coresidence; overt courting behavior such as kissing, arm holding, giving presents, etc., in public; or unambiguous covert courting behavior such as repeated meetings at a man's "batchy"), or were deduced from the genealogies (i.e., relationships that produced one or more offspring). In almost all cases all three sources of information overlapped and were congruent.

At the time of the fieldwork, there were 31 adult coresidential mating relationships (i.e., mates reportedly slept and ate in the same house for more than $90 \%$ of the days of the study period).

There were an additional 48 adult mating relationships, consisting of 7 part-time (more than $10 \%$, but less than $90 \%$ sleeping and eating together) coresidential mating relationships, 28 nonresidential (less than $10 \%$ sleeping and eating together) mating relationships that had been maintained for more than 6 months, and 13 nonresidential mating relationships that had been maintained less than 6 months.

Out of the 91 total mating relationships, 50 were exclusive (monogamous), and 41 were nonexclusive (polygamous). ${ }^{3}$ To examine mate com-

\footnotetext{
${ }^{3}$ These figures on the frequencies of different types of mating relationships agree with other ethnographic studies of Caribbean populations (e.g., Clarke 1957; Gonzalez 1969; Smith 1962; Blake 1961).
} 
petition, individuals that were competing for the same mates were identified (from the nonexclusive relationships). A total of 27 male-male dyads were competing for the same women, and a total of 36 female-female dyads were competing for the same men. For example, if two men (Mr.A and Mr.B) each have a mating relationship with the same woman (Ms.X), there is one male-male dyad (A-B) competing with each other for the same woman; if three men (Mr.A, Mr.B, and Mr.C) are courting the same woman, there are three male-male dyads (A-B, A-C, and B-C); if the same three men are courting the same two women (Ms.X and Ms.Y), there still are only three male-male dyads, but now there is a female-female dyad (X-Y) competing with each other for the same men. In the following section (Results), the scan data are analyzed to determine if the behavioral interactions occurring between individuals competing for the same mate(s) are more agonistic than the interactions occurring between noncompeting individuals.

\section{Resource Control}

To test the hypothesis that females guard males with substantial heritable resources more intensely than males with little or no heritable sources, associations between land ownership and mate guarding are analyzed. To simplify the analysis, land ownership is defined as a dichotomous variable. About half of the adult village males were from households owning 6 or more acres of land $(N=24)$, and half were from households owning less than 6 acres $(N=29)$.

Information about economic assets and occupations was collected by interview (e.g., What land do you own, rent, cultivate? What major possessions do you own-house, mule, radio?). This survey was conducted directly with informants at their place of residence, and in some cases, was corroborated by interviews with other villagers. Government land ownership maps were useful for corroborating information about land ownership (especially the precise size of landholdings, or at least the government's measurement of the acreage) and for establishing patterns of "legal" inheritance.

In this paper land ownership is used as the measure of heritable resources, because: (1) land ownership was much more stable over time than income or ownership of other material items, (2) land was the most valuable resource inherited by most villagers, and (3) land was measured more accurately and reliably than other economic assets. Land ownership is strongly associated with income $(r=0.77, p<0.01)$ and other measures of wealth (Flinn 1983). Both land ownership and income are associated with mating success for males (Flinn 1983, 1986). I use household land as a measure of individual land ownership because land is worked jointly by household family members, the benefits are distributed among household family members, and land is not always "owned" by specific individuals (for discussion of land tenure in Caribbean societies, see Besson 1979). No adjustment for the number of household members was made because this was difficult to do 
appropriately, and because there seemed to be no reason why not adjusting for household size would bias the results for or against any of the hypotheses tested.

\section{Residence}

Information about where individuals resided in the village was obtained by interview and corroborated by incidental observation. Some individuals had multiple residences. For example, a number of children would stay with their grandparents or other relatives while their parent(s) were away working outside of the village. And some mating relationships involved part-time cohabitation. Coresident mates are defined as unrelated adult male-female pairs that sleep in the same house together more than $90 \%$ of the time, regularly eat meals together, and reportedly are sexual partners.

\section{General Remarks}

The data analyzed in this paper are complete for each villager. That is, behavior (scan sample), genealogies of at least two generations in depth, current mating relationships (as defined above), and residence are known for each of the 342 individuals in the village population.

\section{RESULTS}

As in other human societies, fidelity was a concern of most adults in the village of Grande Anse, and not without season: 13 out of 79 (16.4\%) offspring born in the village during the period 1970-1980 were putatively fathered by males other than the mother's coresident mate. Clearly, mate guarding could have significant effects on fitness. In the following sections several hypotheses based on mate guarding theory are tested with the fieldwork data. The analysis focuses on (1) patterns of interaction among individuals competing for the same mates, (2) patterns of interaction among coresident mates according to whether the mating relationship was exclusive (monogamous) or nonexclusive (polygamous), and (3) patterns of interaction among coresident mates according to the reproductive condition (fecundity) of the female.

\section{Mate Competition: Intrasexual Aggression}

Let us consider first the simple prediction that individuals competing for the same mate have a higher rate of agonistic interactions with each other than 


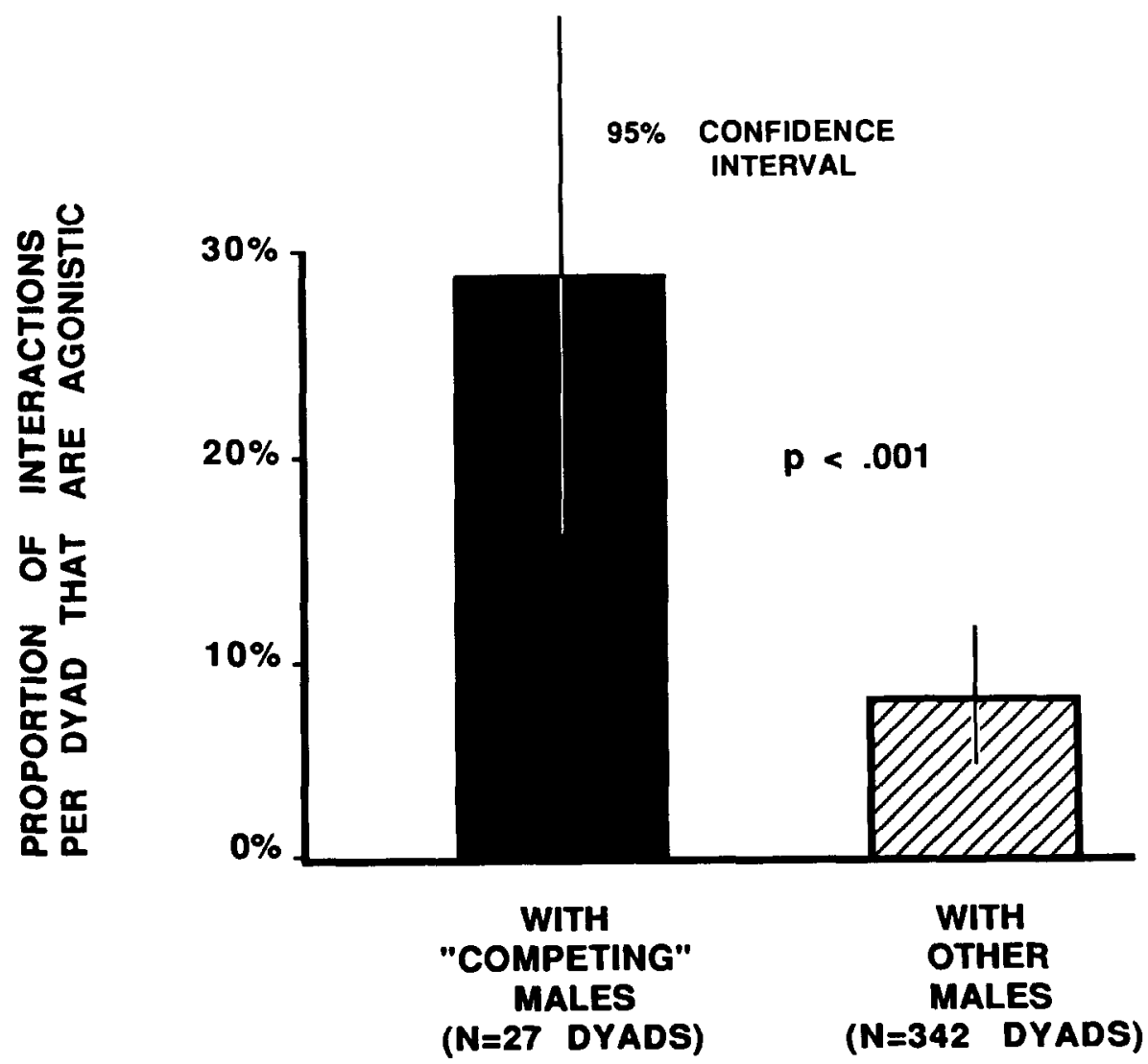

FIGURE 1. Males competing for the same females have a higher frequency of agonistic interactions with each other than they do with other (noncompeting) males. Sample includes males aged $20-45$ years. $X=29.1 \%$ and $\mathrm{SE}=7.11 \%$ for agonistic interactions between competing males. $X=8.6 \%$ and $\mathrm{SE}=1.27 \%$ for agonistic interactions between noncompeting males. $\chi^{2}=28.4$, significant at $p<0.001$ (nonparametric tests are used on the behavioral data because the assumption of normality may not be met by the distribution of the behavioral frcquencies). Fisher's exact tests for differences within 8-year age categories were significant at $p<0.05$. For illustrative purposes, $95 \%$ confidence intervals $(X \pm 1.96 \times \mathrm{SE})$ are shown by the vertical lines. Note: standard error is abbreviated SE.

they do with a control sample of other individuals of equivalent ages and sex.

Figure 1 indicates that males "competing" for (see Methods) the same females had a higher frequency of "agonistic" interactions (see Methods) with each other than they did with other males (nonrelatives) of equivalent ages (same 8-year age category as the "competitor").

Figure 2 indicates that females "competing" for the same males did not have a higher frequency of agonistic interactions with each other than they did with other females (nonrelatives) of equivalent ages. 


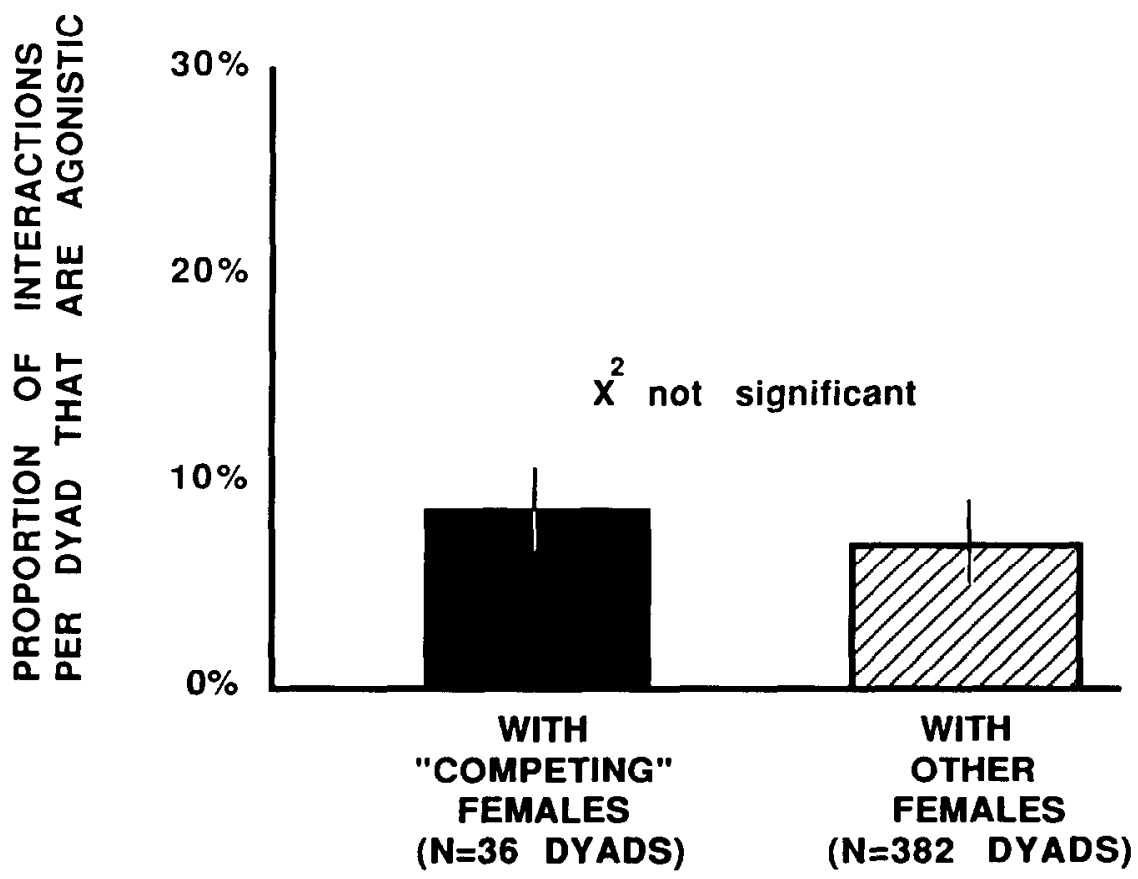

FIGURE 2. Females competing for the same male(s) do not have a higher frequency of agonistic interactions with each other than they do with other (noncompeting) females. $\chi^{2}=0.77$, NS. Sample includes females aged 18-40 years.

FIGURE 3. The frequency of agonistic interactions among exclusive (monogamous) mating relationships is lower than among nonexclusive (polygamous) mating relationships. Sample includes all adult coresidential pairs. For exclusive mating relationships, $X=5.4 \%$ and $\mathrm{SE}=1.7 \%$. For nonexclusive mating relationships, $X=$ $10.6 \%$ and $\mathrm{SE}=2.4 \% \cdot \chi^{2}=4.1, p<0.05$. Sample includes all adult coresidential mating relationships.
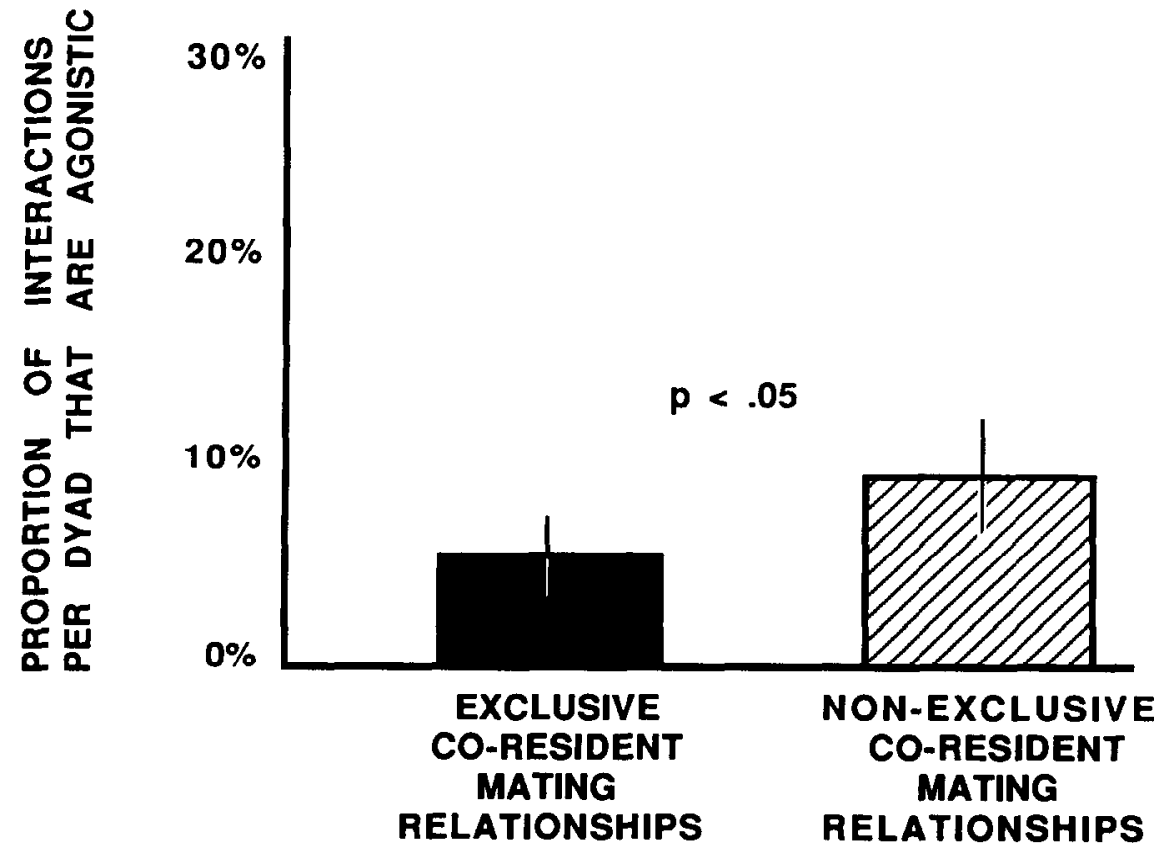


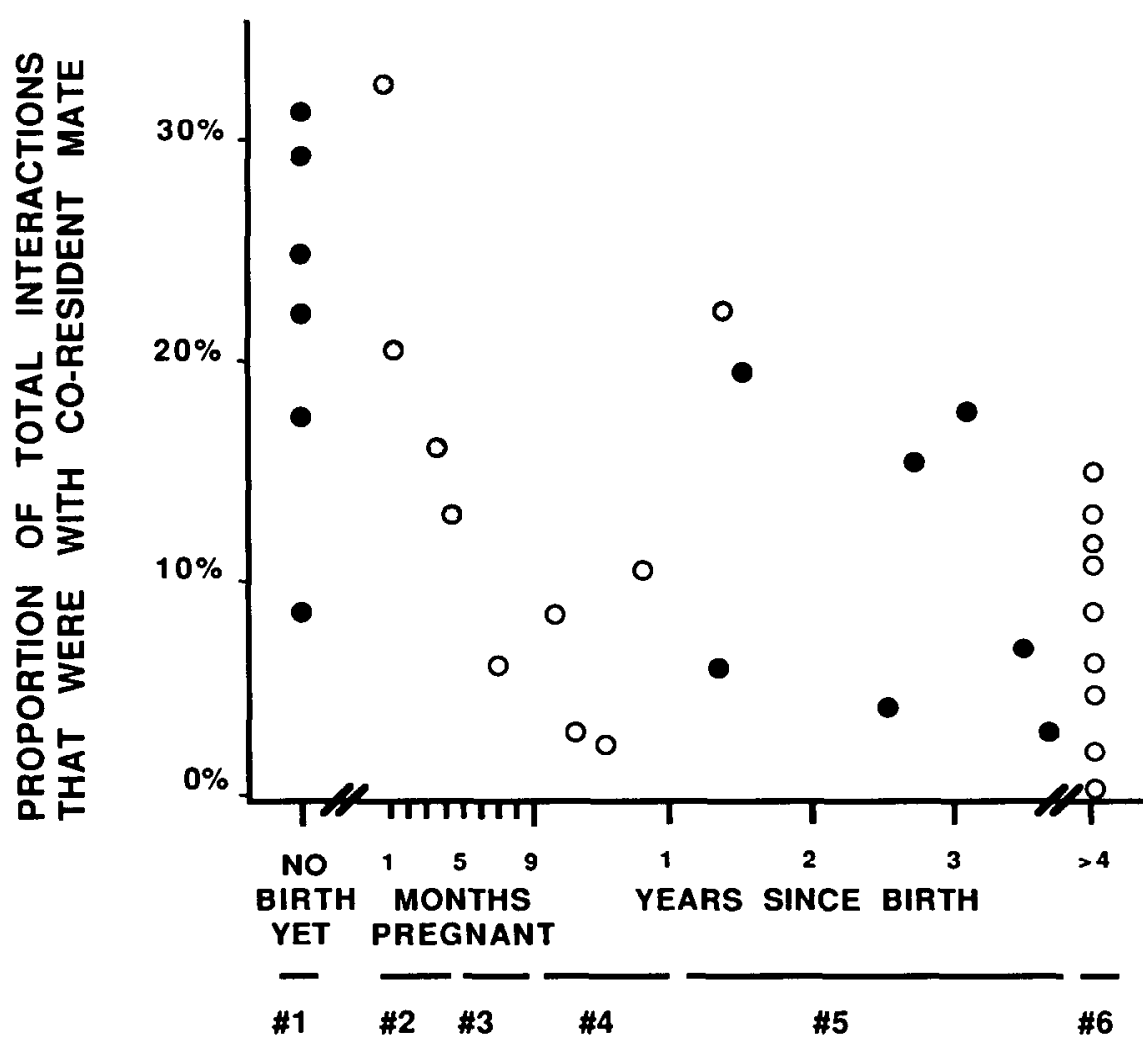

REPRODUCTIVE CONDITION OF FEMALE

FIGURE 4. The frequency of interaction among coresident mates varies according to the reproductive condition of the female. Mates have high rates of interaction before the birth of their first child (\#1), during the first few months of pregnancy (\#2), and after 1 year, but less than 4 years, since the birth of child (\#5). Mates interact less frequently during the latter months of pregnancy (\#3), during the first year after the birth of a child (\#4), and after 4 years since the birth of a child (\#6). The date of reference for reproductive condition is February 1, 1980, about the midpoint of the study. The data points, therefore, have a 3-month time bracket on either side, because the behavioral frequencies are computed from observations of behavior over a 6-month period. Solid dots represent mating relationships that are in potentially fecund reproductive conditions. Empty dots represent mating relationships in less fecund or infecund reproductive conditions. Stippled dots represent mating relationships that underwent a transition from fecund to infecund or vice versa during the period of the field study (e.g., several women became pregnant during the study).

\section{Mate Control: Intersexual Aggression}

Figure 3 shows the frequency of agonistic interactions between coresidential mates according to whether or not the relationship was "exclusive" (both partners monogamous during the period of the field study; see Methods). 


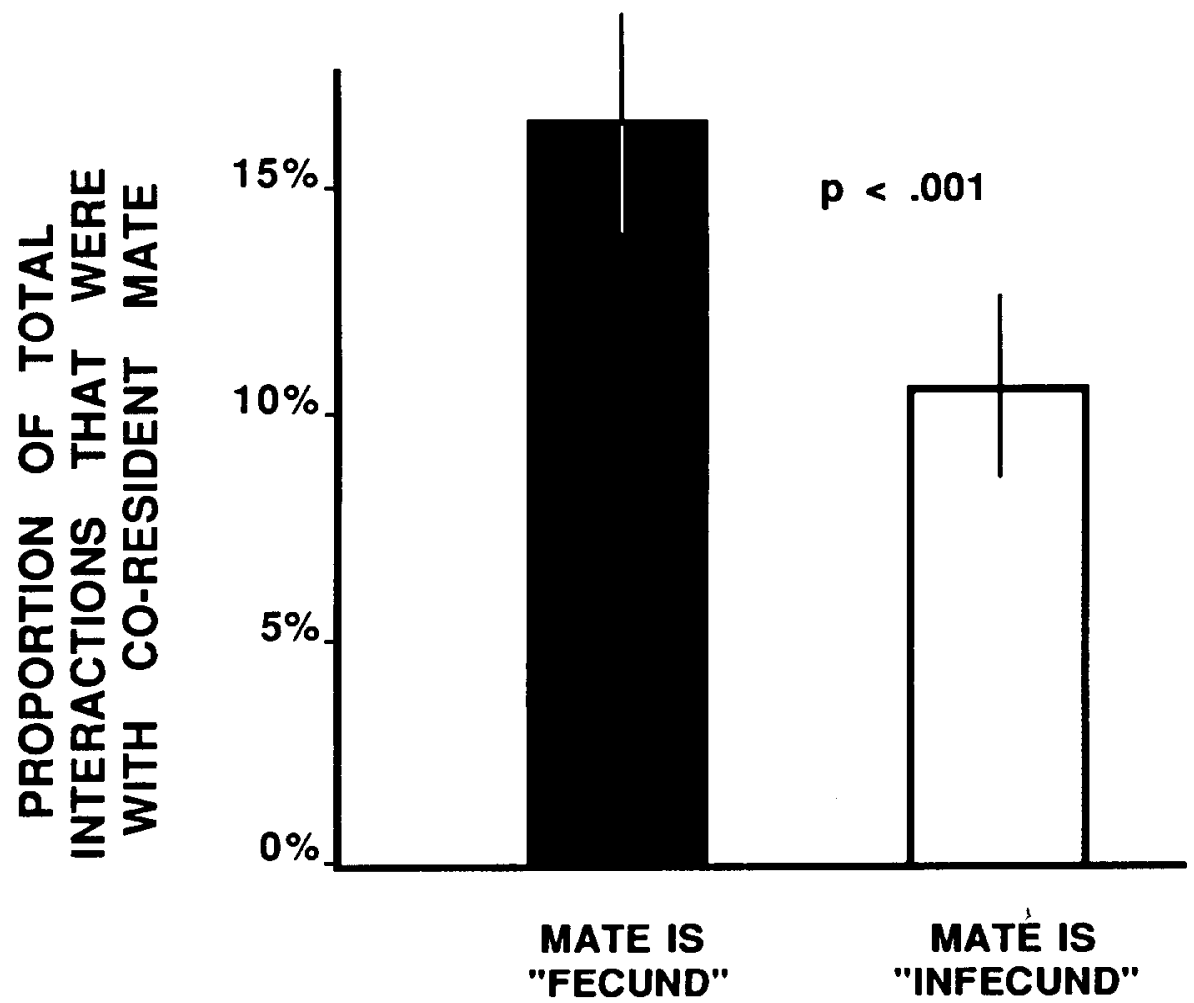

FIGURE 5. Coresident mates interact more frequently when the female is in fecund reproductive conditions ( 1 and 5) than when she is in less fecund or infecund conditions $(2,3,4$, and 6). Data are the same as illustrated in Figure 4. For fecund conditions $X=16.93$ and $\mathrm{SE}=2.5 \%$. For infecund conditions $X=10.5 \%$ and $\mathrm{SE}$ $=1.8 \% \cdot \chi^{2}=23.7$, significant at $p<0.001$. Fisher exact tests for differences within 8 -year age categories were significant at $p<0.05$. Vertical bars represent $95 \%$ confidence intervals.

Exclusive mating relationships have lower frequencies of agonistic interactions between coresident mates than do nonexclusive mating relationships

\section{Reproductive Condition of the Female}

Let us now consider the hypothesis that mates with higher reproductive potential are guarded more intensely than mates with lower reproductive potential.

Figure 4 shows the frequency of interaction among coresident mates according to the reproductive condition of the female. The frequency of interaction between mates appears to vary according to reproductive condition. Most striking is the apparent decrease in the frequency of interaction during the last few months of pregnancy and the first year after birth.

Figure 5 indicates that the frequency of interaction between mates is 


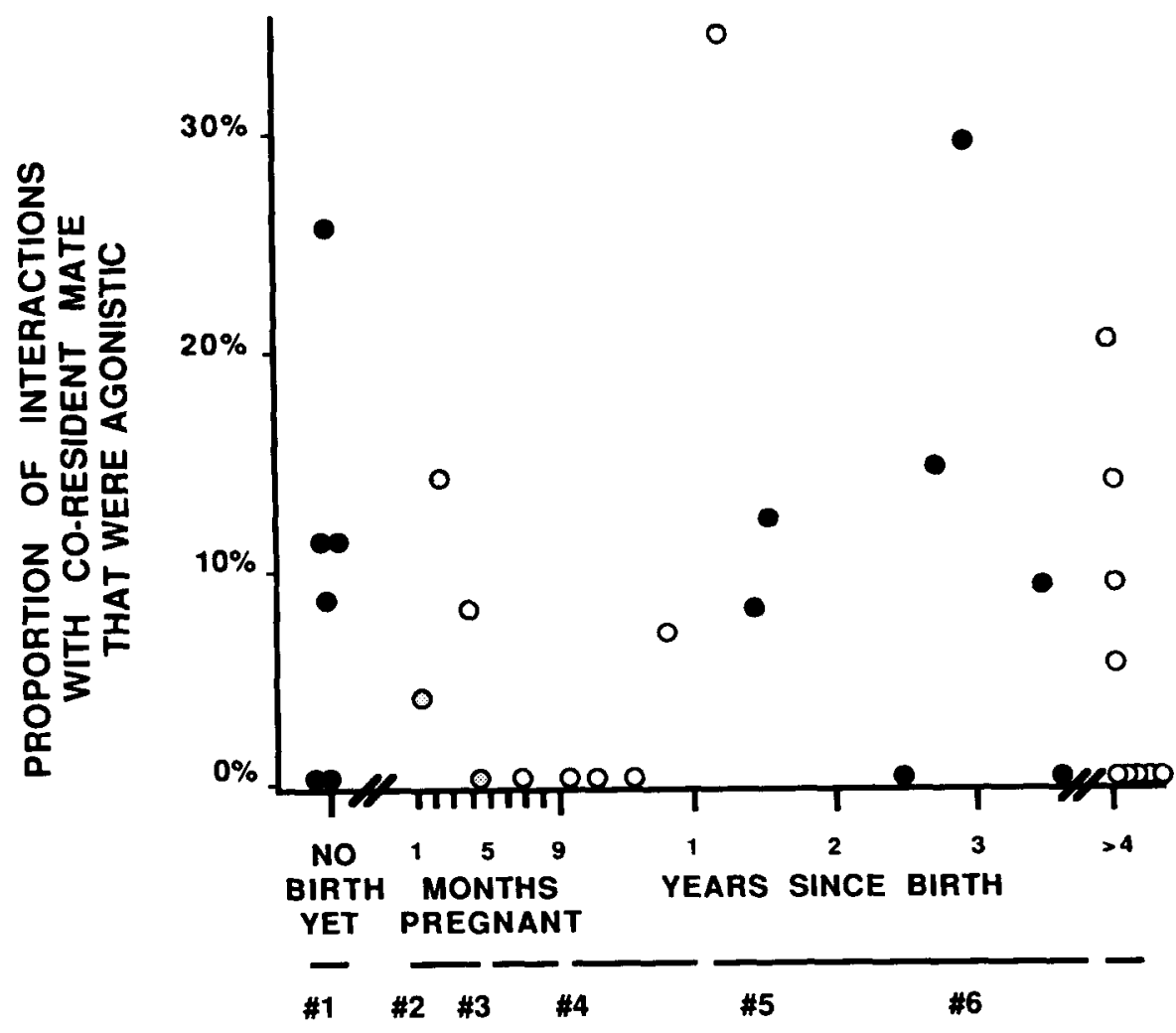

\section{REPRODUCTIVE CONDITION OF FEMALE}

FIGURE 6. The frequency of agonistic interactions between coresident mates during different reproductive conditions of the female. Data are from the same mating relationships as Figure 4. The rates of agonistic interactions seem to be highest before pregnancy and after 1 year, but less than 4 years, since the birth of a child. Dot coloration is the same as in Figure 4.

higher when the female is "fecund" (conditions 1 and 5; see Methods) compared to when the female is "infecund" (conditions 2, 3, 4, and 6). However, there is a general decrease in the interaction frequency among mates with age (mean ages for the six categories are: $21.4,26.9,25.8,26.1,28.3$, and 33.7 years; for the fecund group mean age $=25.2$ years, compared to 30.0 years for the infecund group). To control for the effects of age, the rates of interaction between mates in fecund vs infecund mating relationships were analyzed within 8-year age categories (females aged 18-25, 26-33, and 3440 years). Again, the rates of interaction were higher among fecund mates than among infecund mates (Fisher exact test, $p<0.05$ for each 8-year category).

Figure 6 shows the frequency of agonistic interactions (as a percent of 


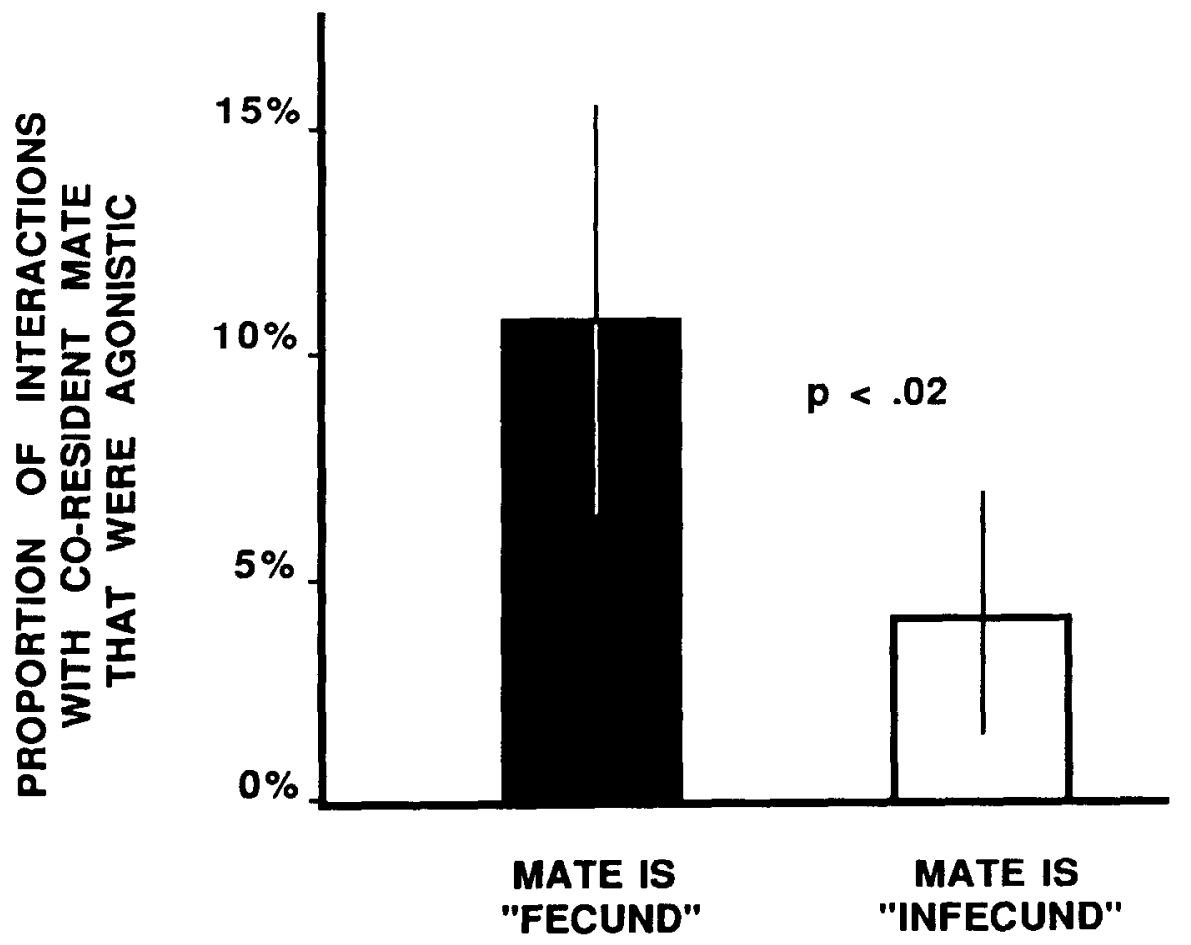

FIGURE 7. When the female is in fecund reproductive conditions, coresident mates have a higher frequency of agonistic interactions. These data suggest that males are "guarding" fecund mates more intensely than infecund mates. $X=12.1 \%$ and SE, $=2.8 \%$ for fecund mates. $X=4.5 \%$ and $\mathrm{SE}=1.4 \%$ for infecund mates. $\chi^{2}=6.36$, significant at $p<0.02$. Fisher exact tests for differences within 8-year age categories were significant at $p<0.01$. Vertical bars represent $95 \%$ confidence intervals.

total interactions) between coresident mates according to the reproductive condition of the female. Figure 7 indicates that the frequency of agonistic interactions between coresident mates is higher when the female is in fecund reproductive conditions than when the female is in infecund conditions.

Figure 8 shows the frequency of agonistic interactions between unrelated males $(r<0.125)^{4}$ according to the reproductive condition of their mates. Figure 9 indicates that there is a significant tendency $\left(\chi^{2}, p<0.05\right)$ for males with fecund mates to have a higher frequency of agonistic interactions with unrelated males than do males with infecund mates, but as in Figures 5 and 7 there is a substantial difference in the mean ages of the groups. Controlling for age by comparison of 8-year age categories indicates

${ }^{4}$ Closely related males (brothers, fathers, sons, half-brothers, uncles, nephews, and first cousins) are excluded from this analysis because kinship is associated with lower frequencies of agonistic interaction (M.V. Flinn, in preparation). I also excluded dyads that involved "daughter guarding" because fathers of teenage daughters have high rates of agonistic interactions with some young males in the village (Flinn 1987). 


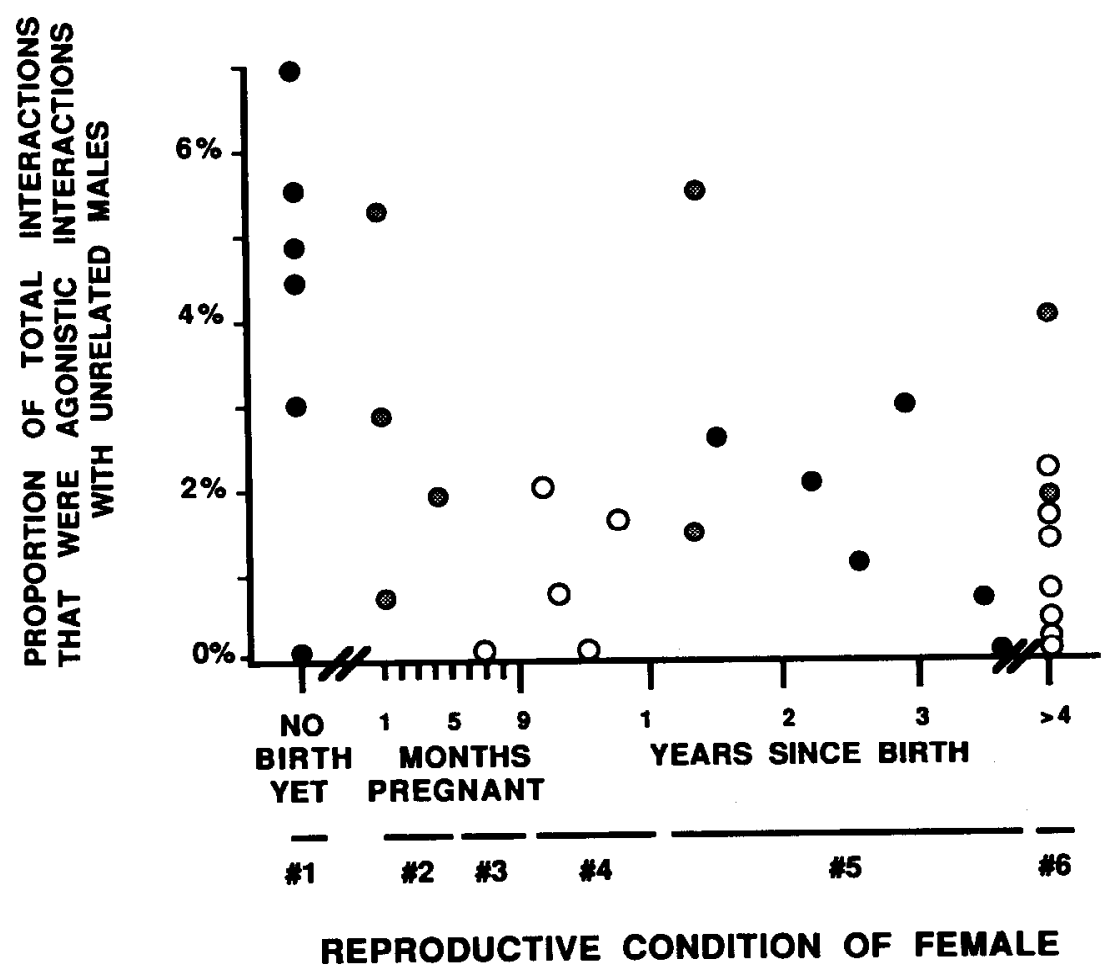

FIGURE 8. The frequency of agonistic interactions between a man and unrelated males during different reproductive conditions of the man's mate. Data are from the same mating relationships as illustrated in Figures 4 and 6. The rates of agonistic interactions seem to be highest before pregnancy and after 1 year, but less than 4 years, since the birth of a child. Dot coloration is the same as in Figures 4 and 6 .

a significant difference between the fecund and infecund groups (Fisher exact tests, $p<0.05$ ).

Figure 10 indicates that, in contrast to males, female agonistic behavior does not seem to be associated with reproductive condition $\left(\chi^{2}, N S\right)$.

Another consideration germane to mate guarding by females is the amount of parental investment that a male has, because females might be expected to guard "high-investment" males more intensely than "low-investment" males. The prediction here is that landed males should be guarded more intensely than the males with little or no land. There is no significant difference in the frequency of agonistic interactions between females depending on the amount of land owned by their coresident mates, but there is a difference in the frequency of agonistic interactions between coresident mates, with higher rates of agonistic interactions with landed males $\left(\chi^{2}, p\right.$ $<0.1$ ). However, because landed males are much more likely to have polygynous mating relationships (Flinn 1986), this could be the cause of the conflict. There is no significant association between land ownership and the 


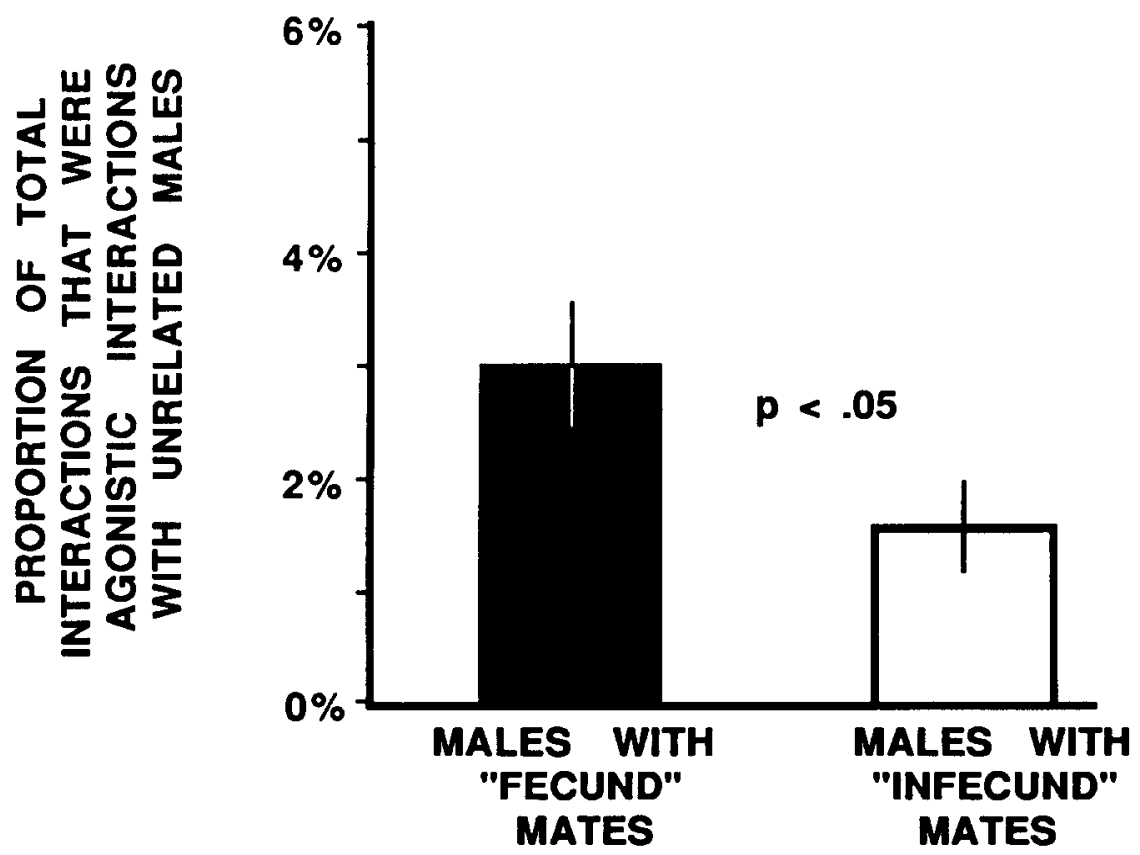

FIGURE 9. When their coresident mates are in fecund reproductive conditions, males have a higher frequency of agonistic interactions with unrelated males. These data suggest that males are "guarding" fecund mates more intensely than infecund mates. $X=2.97 \%$ and $\mathrm{SE}=.59 \%$ for males with fecund mates. $X=1.6 \%$ and $\mathrm{SE}$ $=34 \%$ for males with infecund mates. $\chi^{2}=4.38$, significant at $p<0.05$. Fisher exact tests for differences within 8-year age categories were significant at $\mathrm{p}<0.05$. Vertical bars represent $95 \%$ confidence intervals.

FIGURE 10. The frequency of agonistic interactions among females according to reproductive condition. Females in fecund conditions do not have higher rates of agonistic interactions with other females than do females in infecund conditions. $\chi^{2}$ $=1.8$, NS.

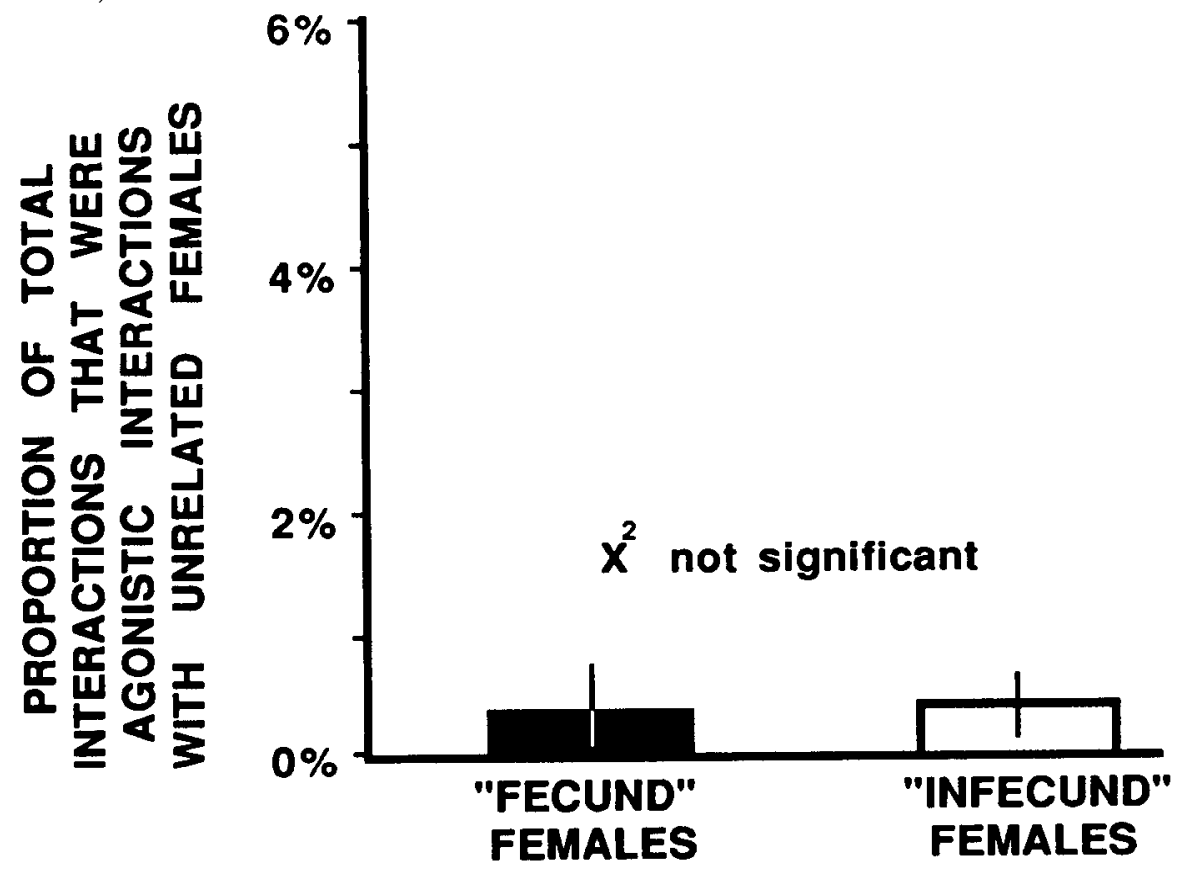


frequency of agonistic interactions between mates in exclusive mating relationships nor in nonexclusive mating relationships.

In summary, the data indicate that: (1) Males competing for the same females have a higher frequency of agonistic interactions with each other than they do with other males of equivalent ages. (2) Females competing for the same males do not have higher rates of agonistic interactions with each other than they do with other unrelated females of equivalent ages. (3) There is a higher frequency of agonistic interactions between coresident mates in nonexclusive mating relationships than between coresident mates in exclusive relationships. (4) In comparison with males with infecund mates, males with fecund mates interact more frequently with their mates, and have higher frequencies of agonistic interactions with their mates. (5) In comparison with males with infecund mates, males with fecund mates have a higher frequency of agonistic interactions with other males. (6) In comparison with infecund females, fecund females do not have higher rates of agonistic interactions with other females. (7) Females do not appear to guard land-rich males more intensely than land-poor males.

\section{DISCUSSION}

The data indicate several significant results. First, males competing for the same females are more likely to quarrel and fight with one another than they are with other males of equivalent ages (Figure 1). This is hardly a surprising result (see Daly et al. 1982; Daly and Wilson 1983; Lee 1979), but it does suggest that the behavioral scan data are useful for analyses of complex social relationships.

In contrast to males, females competing for the same males do not have higher rates of agonistic interactions with each other than with other females of equivalent ages (Figure 2). This does not demonstrate, however, that there are no conflicts of interest between women competing for the same man. Men in Grande Anse express a dislike of overt female competition, and this sentiment probably affects female behavior. Fights or quarrels between women over a man are considered an embarrassment to him, and may reduce his chances of maintaining polygynous relationships. This seems to be common in Caribbean societies (e.g., Malefijt and Hellerman 1973; Otterbein 1966; Smith 1962). Villagers reported that expenditures by a husband on "other women," rather than actual sexual activity, were a more significant source of antagonism between mates (cf. Daly and Wilson 1983). Mate guarding by females seemed to involve the bartering of reciprocal services (e.g., cooking, cleaning, and sex) with their mates rather than overt physical aggression towards the mate or towards competing females.

The higher rate of agonistic interactions in polygamous mating relationships (Figure 3) suggests that there are greater conflicts of interest in nonexclusive mating relationships. This result is consistent with the predic- 
tion that mate guarding is more intense in nonexclusive mating relationships. It is not certain, however, that the increased agonism represents mate guarding. Moreover, the direction of causality is uncertain (unhappy marriages may lead to polygamy).

The low frequencies of interactions between mates during pregnancy and early infancy (Figures 4 and 5) suggest that males are less interested in guarding infecund mates. Several informants suggested that males were especially likely to initiate "outside" (extramarital) mating relationships when their wives had newborns. This effect might be analogous to the association between polygyny and long postpartum sex taboos (Saucier 1972). Part of the decrease in the frequency of interaction among mates at this time, however, could be due to young women with newborns visiting or staying with their natal families, as the newborn's maternal grandmother usually is an important source of assistance.

The pattern of diminished interaction between mates during pregnancy and early infancy is unlikely to be found in all, or even most, other human populations (cf. Whiting and Whiting 1975). The mating system, kinship network, and kinds of parental behavior occurring in Grande Anse undoubtedly have significant effects on the frequency of interaction among mates. It would not be surprising, for example, to find that among middle-class American families, mates spend more time together during the first year after the birth of a child than they do at other periods. Indeed, one might predict from mating systems theory that in societies where males can make significant contributions to the welfare of their mates or infant offspring, or where mating opportunities outside of "marriage" are scarce or nonexistent, that such a reversal in the pattern of interaction between mates would occur.

The diminished frequency of agonistic interactions between coresident mates during pregnancy and early infancy (Figures 6 and 7) is consistent with the reproductive potential hypothesis. However, the association could be due to other factors, such as reduced aggression towards vulnerable individuals, and increased confluence of interests between mates during these periods.

Although the data presented in Figures 4-7 are consistent with predictions from the "reproductive potential" mate guarding hypothesis, the tests are inconclusive because other factors (e.g. visiting maternal kin during early infancy) could feasibly account for the results. A better test of the hypothesis is the examination of the frequency of intrasexual mate guarding behaviors by males according to the reproductive condition of their mates (Figures 8 and 9). This test has the added benefit of distinguishing between the guarding behavior of males and females, which the mate interaction frequencies presented in Figures 3-7 do not.

The data indicating that males with fecund mates have higher rates of agonistic interactions with other males (Figures 8 and 9) are perhaps the most convincing evidence of mate guarding in this population. Preliminary investigation indicates that some males with infecund coresident mates are 
competing for other females, and evidently as a result have high frequencies of agonistic interactions. Consideration of this competition for females "outside" of the coresidential mating relationship appears to strengthen the association between female fecundity and male aggression, but awaits further study.

The lack of association between female aggression towards female competitors and female reproductive condition (Figure 10) could be due to a number of factors. First, female mate guarding apparently does not involve agonistic interactions with rivals (Figure 2). Second, the motivation for mate guarding by females may not vary according to her reproductive condition, if male parental investment is the motivation for mating guarding (although one might expect females with newborns to be especially anxious to receive immediate paternal care). Third, there is no parallel to the changes in female fecundity among males; simply put, males do not get pregnant, and usually are continuously fertile.

The extent to which mates are guarded in Grande Anse is quite limited compared to the drastic measures that are taken in some other socieites. There is no binding of the feet, no veiling of the face, no female genital mutilation, no divorce or death penalty for adultery, no infant betrothal, and no arranged cousin marriage. There also are no inherited positions of status, and no major differences among villagers in the possession of material resources, unlike societies with the more intense guarding behaviors listed above (see Dickemann 1981). As in most other human societies, however, there evidently is overt and covert competition for mates.

\section{SUMMARY AND CONCLUDING REMARKS}

Some conditions associated with mate guarding behaviors in nonhuman species are associated with mate guarding by the people of Grande Anse as well: (1) Fecund mates are guarded more intensely than infecund mates, and (2) males are more likely than females to use physical aggression to guard their mates.

These results indicate that we cannot easily reject an evolutionary model of human mating behavior. In combination with genealogical, economic, and residence information, the behavioral scan data suggest that mate competition and guarding are significant sources of conflict among villagers and an important aspect of mating relationships. The data also provide a useful baseline for comparison with other societies.

That humans have the capacity for sexual jealousy (and resultant aggression) is obvious to any postpubertal member of our species. The extent to which such emotions and behavior are products of our evolutionary history, and the extent to which they serve adaptive functions in cultural environments, however, are controversial issues (Symons 1979; Lancaster 1979). The data presented here, particularly the results indicating that mating re- 
lationships vary according to the reproductive potential of the female, suggest additional avenues for research.

Among many nonhuman primates and other mammals, females exhibit observable indications of the timing of ovulation ("estrous signals"). Malemale aggression increases in many primate species when estrous females are present (e.g. , brown capuchins: Janson 1984; grey langurs: Boggess 1980; Mohnot 1984; savannah baboons: Rasmussen 1980; Collins 1981; chimpanzees: Nishida 1983), and sexual "consortships" appear to be most intense during estrous (e.g., chimpanzees: Wrangham 1975, 1986; Tutin, 1980; Tutin and McGinnis 1981; savannah baboons: Rasmussen 1980; see also Lancaster and Lee 1965; DeVore and Hall 1965).

Human females, in contrast, do not exhibit any obvious outward signals of ovulation; indeed, it is common for the timing of ovulation to be unknown (consciously) even to the female herself. Why human females evolved "concealed ovulation" is a fascinating and controversial issue (Alexander and Noonan 1979; Benshoof and Thornhill 1979; Burley 1979; Strassmann 1981; Symons 1979; Hrdy 1981; Turke 1984; Ember and Ember 1984). There are, however, some studies that suggest that the timing of ovulation among human females is not entirely concealed. For example, human females living in close proximity (e.g., college dorms) are known to synchronize their menstrual cycles (McClintock 1971, 1981; Graham and McGrew 1980; Tucker 1986), indicating that some communication (probably pheromonal) is occurring. And some studies of human female heterosexual motivation indicate a peak in interest around the time of ovulation (Adams et al. 1978; McCance et al. 1952; Udry and Morris 1968). These studies suggest that the timing of ovulation may not be completely concealed from human males (cf. Doty et al. 1975).

It occurred to me in the later stages of the field research (largely as a result of informal discussions with friends in the village) that information about the timing of menstrual cycles among village residents could be useful for testing hypotheses about mate guarding. I am unaware of any ethnographic information that could be used to test whether or not mate guarding is more intense during the probable time of ovulation (although cross-cultural studies indicate that sexual activity is commonly tabooed or otherwise avoided during menstruation; see Paige and Paige 1981; Stephans 1961; Frayser 1985; Asherian et al. 1986). I plan to gather such information in future field research.

I would like to thank Richard Alexander, Duncan Anderson, Laura Betzig, Robbins Burling, David Buss, Martin Daly, Paul Sherman, Margo Wilson, Richard Wrangham, and three anonymous reviewers for helpful comments on the manuscript, and Arinthia, Junior, Andre, and Susan for assistance with the fieldwork. The research was supported by grants from the Hill Foundation and the University of Michigan Society of Fellows. 


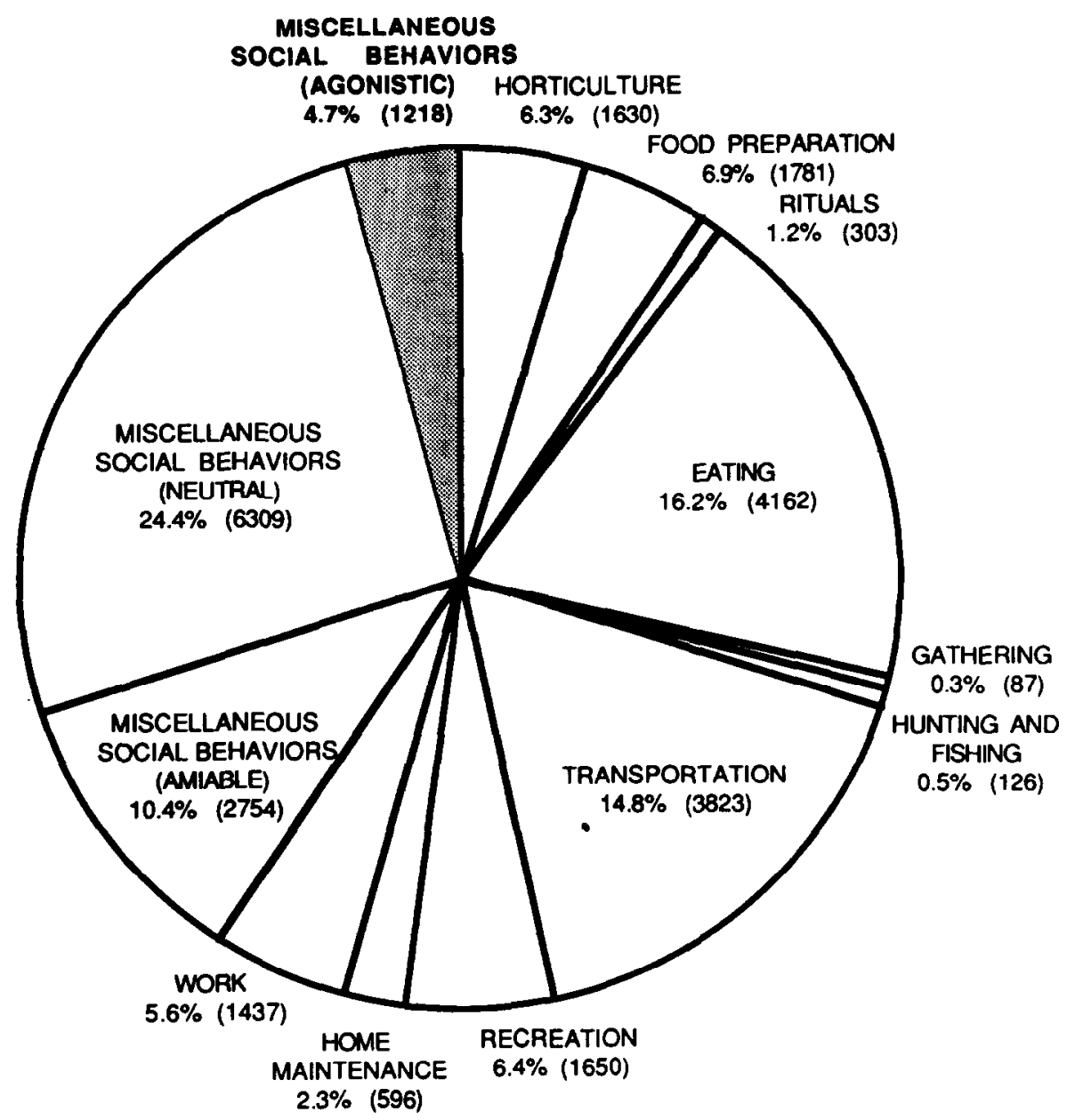

FIGURE 11. The frequencies of observed behaviors (in parentheses) grouped into thirteen major categories.

\section{APPENDIX}

The frequencies of the different cateogires of behaviors are presented in Figure 11. The specific behavior codes and frequencies include in the category "agonistic interactions" are listed below. Note that only 92 out of $1218(7.5 \%)$ observations involved actual physical agonism, although in some cases physical agonism occurred before or after observed threats or verbal agonism.

804 Fighting - serious (involving physical contact with the potential for substantial injury) with weapons (e.g. bottle, cutlass) (number of observations $=2,0.2 \%$ of all agonistic interactions)

805 Fighting-serious, but no weapons (e.g. fist fighting) $(5,0.4 \%)$ 
806 Fighting-moderate (few substantial blows) $(7,0.6 \%)$

807 Fighting - "play," but with some substantial blows or tumbles (cf. no. $515)(23,1.8 \%)$

808 Fighting by throwing stones (or using slingshot) $(12,1.0 \%)$

809 Fighting using sticks $(4,0.3 \%)$

813 Threatening to fight an individual (I.D. no.) using weapons (verbal threats and gesturing with weapon)-in the presence of the threatened individual $(3,0.2 \%)$

814 Threatening to fight an individual (I.D. no.) using weapons (verbal threats and gesturing with weapon)-not in the presence of the threatened individual $(5,0.4 \%)$

815 Threatening to fight an individual (I.D. no.) in a nonserious way (e.g., just the threat of a slap)-in the presence of the threatencd individual $(38,3.1 \%)$

816 Threatening to fight an individual (I.D. no.) in a nonserious way-not in the presence of the threatened individual (e.g., "I'm going to beat that girl when she gets home') $(23,1.8 \%)$

817 Threatening to punish an individual (I.D. no.) - not serious (e.g., a mother stating that she will not give "candy money" to her child if . . .) $(127,10.4 \%)$

818 Threatening to punish an individual (I.D. no.)-serious (e.g., a father stating that he is going to physically punish a child if . . ) $(52,4.3 \%)$

829 Glaring at someone (I.D. no.) (14, 1.1\%)

847 Arguing-insubstantial, but "unfriendly" (e.g., raised voices) (251, 20.6\%)

848 Arguing-substantial (e.g., concerning a debt) $(44,3.5 \%)$

856 Insulting someone deliberately (I.D. no.) $(32,2.6 \%)$

857 Cussing someone (I.D. no.) $(38,3.1 \%)$

867 Family quarrel concerning extra marital relations $(16,1.3 \%)$

870 Criticizing someone (I.D. no.) in their presence-trivial $(132,10.8 \%)$

871 Criticizing someone (I.D. no.) not in their presence-trivial $(209,17.2 \%)$

872 Criticizing someone (I.D. no.) in their presence-serious (e.g., accusation of theft or stinginess) $(24,1.8 \%)$

873 Criticizing someone (I.D. no.) not in their presence-serious $(67,5.5 \%)$

875 Yelling at someone (I.D. no.) $(41,3.3 \%)$

876 Screaming with pain $(17,1.4 \%)$

877 Crying $(23,1.8 \%)$

990 Theft $(3,0.3 \%)$

992 Deliberate damage to another's (I.D. no.) property $(6,0.5 \%)$

\section{REFERENCES}

Adams, D.B., Gold, A.R., and Burt, A.D. Rise in female-initiated sexual activity at ovulation and its suppression by oral contraceptives. New England Journal of Medicine 229: $1145-1150$ (1978). 
Alexander, R.D. The evolution of social behavior. Annual Review of Ecology and Systematics 5: 325-383 (1974).

- Darwinism and Human Affairs. Seattle: University of Washington Press, 1979.

- and Borgia, G. On the origin and basis of the male-female phenomenon. In Sexual selection and Reproductive Competition in Insects, M.F. Blum and N. Blum, eds. New York: Academic Press, 1979, pp. 417-440.

- and Noonan, K.M. Concealment of ovulation, parental care, and human social evolution. In Evolutionary Biology and Human Social Behavior. N. Chagnon and W. Irons, eds. North Scituate, MA: Duxbury Press, 1979, pp. 436-453.

Altmann, J. Observational study of behavior: sampling methods. Behaviour XLIX: 227-266 (1974).

Asherian, A., Flinn, M.V., and Rosenberg, A. Menstrual seclusion: a male strategy? Paper delivered at the annual meetings of the Midwestern Evolution and Human Behavior Group, Ann Arbor, MI, April 1986.

Bateman, A.J. Intra-sexual selection in Drosophila. Heredity 2: 349-368 (1948).

Beecher, M.D., and Beecher, I.M. Sociobiology of bank swallows: reproductive strategy of the male. Science 205: 1282-1285 (1979).

Benshoof, L., and Thornhill, R. The evolution of monogamy and concealed ovulation in humans. Journal of Social and Biological Structures 2: 95-106 (1979).

Besson, J. Symbolic aspects of land in the Caribbean: The tenure and transmission of land rights among Caribbean peasantries. In Pesants, Plantations and Rural Communities in the Caribbean. M. Cross and A. Marks, eds. Department of Sociology, University of Surrey, and Department of Caribbean Studies, Royal Institute of Linguistics and Anthropology, 1979, pp. 85-116.

Betzig, L.L. and Turke, P.W. Parental investment by sex on Ifaluk. Ethology and Sociobiology 7:29-37 (1986).

Birkhead, T.R. The timing and duration of mate-guarding in magpies Pica pica. Animal Behaviour 30: 277-283 (1982).

- Johnson, S.D. and Nettleship, D.N. Extra-pair matings and mate guarding in the common murre Uria aalge. Animal Behaviour 33: 608-619 (1985).

Blake, J. Family Structure in Jamaica New York: Free Press, 1961.

Blurton-Jones, N., ed. Ethological Studies of Child Bchavior. Cambridge: Cambridge University Press, 1972.

Boggess, J.E. Intermale relations and troop male membership changes in langurs (Presbytis entellus) in Nepal. International Journal of Primatology 1: 233-274 (1980)

Borgia, G. Sexual selection and the evolution of mating systems. In Sexual Selection and Reproductive Competition in Insects, M.F. Blum and N. Blum, eds. New York: Academic Press, 1979, pp. 19-80.

Burley, N. The evolution of the concealment of ovulation. American Naturalist 114: 835-858 (1979).

Chagnon, N.A. Studying the Yanomamo. New York: Holt, Rinehart and Winston, 1974.

- Is reproductive success equal in egalitarian societies? In Evolutionary Biology and Human Social Behavior. N. Chagnon and W. Irons, eds. North Scituate, MA: Duxbury Press, 1979, pp. 374-401.

- Kin selection theory, kinship, marriage, and inclusive fitness among the Yanomamo Indians. In Sociobiology: Beyond Nature-Nurture, G.W. Barlow and J. Silverberg, eds. AAAS special symposium 35. Boulder CO: Westview Press, 1980.

Terminological kinship, genealogical relatedness, and village fissioning among the Yanomamo Indians. In Natural Selection and Social Behavior: Recent Research and New Theory, R.D. Alexander and D.W. Tinkle eds. New York: Chiron Press, 1981, pp. 490-508.

- Sociodemographic attributes of nepotism in tribal populations: man the rule breaker. In Current Problems in Sociobiology. King's College Sociobiology Group, eds. Cambridge: University of Cambridge Press, 1982.

Yanomamo: The Fierce People 3rd ed. New York: Holt, Rinehart and Winston, 1983.

Clarke, E. My Mother who Fathered Me. London: Allen and Unwin, 1957.

Collins, D.A. Social behaviour and patterns of mating among adult yellow baboons. Ph.D. dissertation, Cambridge University, 1981. 
Daly, M., and Wilson, M.I. Abuse and neglect of children in evolutionary perspective. In Natural Selection and Social Behavior: Recent Research and New Theory, R.D. Alexander, and D.W. Tinkle, eds. New York: Chiron Press, 1981, pp. 405-416.

- Iomicide and kinship. American Anthropologist 84: 372-378 (1982).

- Sex, Evolution, and Behavior. Boston: Duxbury Press, 1983.

- and Weghorst, S.J. Male sexual jealousy. Ethology and Sociobiology 3: 11-27 (1982).

Darwin, C.R. The Descent of Man and Selection in Relation to Sex. New York: Random House, 1871.

Denham, W.W. BEVRECS. In Alyawara Ethnographic Data Base. New Haven: HRAF Press, 1978 .

DeVore, I. and Hall, K.R.L. Baboon ecology. In Primate Behaviour. I. DeVore, ed. New York: Holt, Rinehart and Winston, 1965.

Dickemann, M. The ecology of mating systems in hypergynous dowry societies. Social Science Information 18: 163-195 (1979).

- Paternal confidence and dowry competition: a biocultural analysis of purdah. In Natural Selection and Social Behavior: Recent Research and New Theory, R.D. Alexander and D.W. Tinkle, eds. New York: Chiron press, 1981, pp. 417-438.

Doty, R.L., Ford, M., and Preti, G. Changes in the intensity and pleasantness of human vaginal odors during the menstrual cycle. Science 190: 1316-1318 (1975).

Ember, C.R., and Ember, M. The evolution of human female sexuality: a cross species perspective. Journal of Anthropological Research 40: 202-210 (1984).

Emlen, S.T., and Oring, L.W. Ecology, sexual selection, and the evolution of mating systems. Science 197: 215-223 (1977).

Flinn, M.V. Uterine vs. agnatic kinship variability and associated cousin marriage preferences. In Natural Selection and Social Behavior: Recent Research and New Theory. R.D. Alexander and D.W. Tinkle, eds. New York: Chiron Press, 1981, pp. 439-475.

- Resources, mating, and kinship: The behavioral ecology of a Trinidadian village. Ph.D. thesis, Department of Anthropology, Northwestern University. Ann Arbor, MI: University Microfilms, 1983.

- Correlates of reproductive success in a Trinidadian village. Human Ecology 14(2):225243 (1986).

- Daughter guarding in a Trinidadian village. In Human Reproductive Behavior. L. Betzig, M. Mulder, and P. Turke, eds. London: Cambridge University Press, 1987.

- , and Low, B.S. Resource distribution, social competition and mating patterns in human societies. In Ecological Aspects of Social Evolution. D.I. Rubenstein and R.W. Wrangham, eds. Princeton, NJ: Princeton University Press, 1986.

Fortune, R.F. The Sorcerers of Dobu. New York: Dutton, 1963.

Frayser, S.G. Varieties of Sexual Experience: An Anthropological Perspective on Human Sexuality. New Haven: HRAF Press, 1985.

Gonzalez, N.S. Black Carib Household Structure. Seattle: University of Washington Press, 1969.

Graham, C., and McGrew, W. Menstrual synchrony in female undergraduates living on a coeducational campus Psychoneuroendocrinology 5: 245-252 (1980).

Gross, D. Time allocation: a tool for the study of cultural behavior. Annual Review of Anthropology 1984 13: 519-558 (1984).

Hames, R. Relatedness and interaction among the Ye'kwana: a preliminary analysis. In $E v-$ olutionary Biology and Human Social Behavior. N. Chagnon, and W. Irons, eds. North Scituate, MA: Duxbury Press, 1979, pp. 238-250.

Harreli, B.B. Lactation and menstruation in cultural perspective. American Anthropologist 83: 796-823 (1981).

Harrison, D.H. The changing fortunes of a Trinidad peasantry: A case study In Peasants, Plantations and Rural Communities in the Caribbean. M. Cross and A. Marks, eds. Department of Sociology, University of Surrey, and Department of Caribbean Studies, Royal Institute of Linguistics and Anthropology, 1979, pp. 54-85.

Hartung, J. Polygyny and the inheritance of wealth. Current Anthropology 23: 1-12 (1982).

Hosken, Fran P. The Hosken Report: Genital and Sexual Mutilation of Females. Massachusetts: WIN News (1982).

Howie, P.W., McNeilly, A.S., Houston, M.J., Cook, A., and Boyle, H. Effect of supplemen- 
tary food on suckling patterns and ovarian activity during lactation. British Medical Journal 283: 757-759 (1981).

Hrdy, S. Infanticide among animals: a review, classification, and examination of the implications for the reproductive strategies of females. Ethology and Sociobiology 1: 1240 (1979).

- The Woman That Never Evolved. Cambridge, MA: Harvard University Press, 1981.

Irons, W. Investment and primary social dyads. In Evolutionary Biology and Human Social Behavior. N. Chagnon and W. Irons, eds. North Scituate, MA: Duxbury Press, 1979a, pp. 181-212.

Human female reproductive strategies. In Social Behavior of Female Vertebrates. S. Wasser and M. Waterhouse, eds. New York: Academic Press, 1983, pp. 169-213.

Janson, C.H. Female choice and mating system of the brown capuchin monkey Cebus apella. Zeitschrift fur Tierpsychologie 65: 177-200 (1984).

Jenni, D.A. Evolution of polyandry in birds. American Zoologist 14: 129-144 (1974).

Johnson, A.W. Time allocation in a Machiguenga community. Ethnology 14(3): 310-312 (1975).

Quantification in Cultural Anthropology. Stanford: Stanford University Press, 1978.

Konner, M., and Worthman, C. Nursing frequency, gonadal function, and birth spacing among the !Kung hunter-gatherers. Science 207: 788-791 (1980).

Kouba, L.J, and Muasher, J. Female circumcision in Africa: An overview. African Studies Review 28: 95-111 (1985).

Lancaster, J.B. Sex and gender in evolutionary perspective. In Human Sexuality: A Comparative and Developmental Perspective. H. Katchadourian, ed. Berkeley: University of California Press, 1979, pp. 51-80.

- and Lee, R.B., The annual reproductive cycle in monkeys and apes. In Primate Behavior, I. DeVore, ed. New York: Holt, Rinehart and Winston, 1965, pp. 486-513.

Lee, Richard B. The !Kung San. London: Cambridge University Press, 1979.

Levi-Strauss, C. Les Structures Elementaires de la Parente. Paris: Plon, 1949.

Lumpkin, S. Avoidance of cuckoldry in birds: the role of the female. Animal Behaviour 29: 303-304 (1981).

Lumpkin, S., Kessel, K., Zenone, P.G., and Erickson, C.J. Proximity between the sexes in ring doves: social bonds or surveillance? Animal Behaviour 30:506-513 (1982).

Malefijt, A.W., and Hellerman, M. Aruban mating patterns. In The Family in the Caribbean, S.N. Gerber, ed. Rio Piedras, Puerto Rico: Institute of Caribbean Studies, 1973.

Manning, J.T. Sex ratio and optimal male time investment strategies in Asellus aquaticus (L.) and A. meridianus Racovitsza. Behaviour 74: 265-273 (1980).

McClintock, M.K. Menstrual synchrony and suppression. Nature 229: 244-245 (1971).

Social control of the ovarian cycle and the function of estrous synchrony. American Zoologist 21: 243-256 (1981).

Mohnot, S.M. Langur interactions around Jodhpur (Presbytis entellus). In Current Primate Researches. Jodhpur: University of Jodhpur Press, 1984.

Munroe, R.H., and Munroe, R.L. Household density and infant care in an East African Society. Journal of Social Psychology 85: 3-13 (1971).

Munroe, R.L., Munroe, R.H., Michealson, C., Koel, A., Bolton, R., and Bolton, C. Time allocation in four societies. Ethnology 22: 355-70 (1983).

Nishida, T. Alpha status and agonistic alliance in wild chimpanzees (Pan troglodytes schweinfurthii). Primates 24: 318-336 (1983).

Orians, G. On the evolution of mating systems in birds and mammals. American Naturalist 103:589-603 (1969)

Otterbein, K.F. The Andros Islanders. Lawrence: University of Kansas, 1966.

Paige, K.E., and Paige, J.M. The Politics of Reproductive Ritual. Berkeley: University of California Press, 1981.

Parker, G.A. Courtship persistence and female-guarding as male time-investment strategies. Behaviour 48:157-184 (1974).

- Searching for mates. In Behavioral Ecology, J.R. Krebs and N.B. Davies, eds. London: Blackwell, 1978, pp. 214-244.

Pelto, P.J., and Pelto, G.H. Anthropological research: the structure of inquiry. New York: Harper and Row, 1970.

_ Intra-cultural diversity: some theoretical issues. American Ethnologist 2: 1-18 (1975). 
Rasmussen, K.L.R. Consort behavior and mate selection in yellow baboons (Papio cynocephalus). Ph.D. dissertation, University of Cambridge, 1980.

Rodman, H. Lower Class Families. London: Oxford University Press, 1971.

Rogoff, B. Spot observation: An introduction and examination. Quarterly Newsletter of the Institute of Comparative Human Development, Rockefeller University 2,2C: 21-26 (1985).

Sanday, P.R. Female Power and Male Dominance. Cambridge: Cambridge University Press, 1981.

Saucier, J.-F. Correlates of the long postpartum taboo: a cross cultural study. Current Anthropology 13: 238-249 (1972)

Schlegel, A. Male Dominance and Female Autonomy: Domestic Authority in Matrilineal Societies. New Haven: HRAF Press, 1972.

Sivinski, J. Intrasexual selection in the stick insects, Diapheromera veliei and D. covilleae. and sexual dimorphism in the Phasmatodea. Psyche 85: 395-406 (1978).

Smith. M.G. West Indian Family Structure. Seattle: University of Washington Press, 1962.

Smuts, B.S. Sex and Friendship in Baboons. New York: Aldine, 1985.

Stephans, W. A cross-cultural study of menstrual taboos. Genetic Psychology Monographs 64: 385-416 (1961).

Strassmann, B.I. Sexual selection, parental care. and concealed ovulation in humans. Ethology and Sociobiology 2: 31-40 (1981).

Symons, D. The Evolution of Human Sexuality. Oxford: Oxford University Press, 1979.

Tenaza, R.R. Territory and monogamy among Kloss gibbons in Siberut Island, Indonesia. Folia Primatologica 24: 60-80 (1975).

Thornhill, R., and Alcock, J. The Evolution of Insect Mating Systems Cambridge, MA: Harvard University Press, 1983.

- and Thornhill, N.W. Human rape: an evolutionary analysis. Ethology and Sociobiology 4: $137-173$ (1983).

Trivers, R.L. Parental investment and sexual selection. In Sexual Selection and the Descent of Man 187/-1971. B. Campbell, ed. Chicago: Aldine, 1972.

- Social Evolution. Menlo Park, CA: Benjamin-Cummings, 1985.

Tucker. H. Ovulatory synchrony in humans. Honors thesis, LS\&A, University of Michigan, 1986.

Turke, P. Ph.D. thesis, Department of Anthropology, Northwestern University. Ann Arbor, MI: University Microfilms, 1984.

Tutin, C.E.G. Reproductive behavior of wild chimpanzees in the Gombe National Park, Tanzania. Journal of Reproduction and Fertility, Supplement 28: 43-57 (1980).

and McGinnis, P.R. Chimpanzee reproduction in the wild. In Reproductive Biology of the Great Apes. C.E. Graham, ed. New York: Academic Press, 1981.

Udry, J.R., and N. Morris The distribution of coitus and orgasm in the menstrual cycle in middle- and lower-class women. Nature 200: 593-596 (1968).

Vehrencamp, S., and Bradbury, J. Mating systems and ecology. In Behavioral Ecology, 2nd edition, J.R. Krebs and N.B. Davies, eds. Sunderland, MA: Sinauer Associates Inc., 1984.

Verner, J. and Willson, M.F. The influence of habitats on mating systems of North American passerine birds. Ecology 47:143-147.

Whiting, J.W.M., and Whiting, B.B. Aloofness and intimacy of husbands and wives: a crosscultural study. Ethos 3: 183-207 (1975).

Whyte, M. The Status of Women in Pre-industrial Societies. Princeton: Princeton University Press, 1978.

Wilson, E.O. Sociobiology. Cambridge, MA: Harvard University Press, 1975.

Wrangham, R.W. The behavioral ecology of chimpanzees in Gombe National Park, Tanzania. Doctoral dissertation, Cambridge University, 1975.

- Ecology and social relationships in two species of chimpanzee. In Ecological Aspects of Social Evolution, D.I. Rubenstein and R.W. Wrangham, eds. Princeton: Princeton University Press, 1986.

Zenone. P.G., Sims, M.E., and Erickson, C.J. Male ring dove behavior and the defense of genetic paternity. American Naturalist 114: 615-626 (1979). 